\title{
Measurement of milk intake: tracer-to-infant deuterium dilution method
}

\author{
BY NANCY F. BUTTE, WILLIAM W. WONG, PETER D. KLEIN \\ AND CUTBERTO GARZA \\ USDA/ARS Children's Nutrition Research Center, Department of Pediatrics, Baylor College of \\ Medicine, 1100 Bates Street, Houston, TX 77030, USA
}

(Received 14 February 1990 - Accepted 20 July 1990)

\begin{abstract}
The tracer-to-infant deuterium dilution method for the measurement of milk intake was evaluated in twenty breast-fed and twenty formula-fed infants. The isotope method was compared with conventional direct-weighing techniques. Human milk intake was assessed by $5 \mathrm{~d}$ test-weighing. Intakes of formula, supplemental foods, and water were determined by pre- and post-weighing of feeding bottles. An oral dose of $200 \mathrm{mg}{ }^{2} \mathrm{H}_{2} \mathrm{O} / \mathrm{kg}$ body-weight was given to each infant, and urine was sampled daily for $14 \mathrm{~d}$. ${ }^{2} \mathrm{H}$ enrichment of the urine was measured by gas-isotope-ratio mass spectrometry. Milk intakes estimated from the deuterium dilution method were consistently higher than those from direct-weighing; the mean difference between methods was 106 (SD 47) $\mathrm{g} / \mathrm{d}$ or $14 \%$ for the breast-fed group and 70 (SD $155) \mathrm{g} / \mathrm{d}$ or $8 \%$ for the formula-fed group. Estimates of intake for some infants varied substantially between the two methods of measurement. When the estimated values of human milk intake were corrected for environmental water influx and insensible water loss during breast-feeding, the relative bias decreased to $5 \%$. Correction of the estimated values of formula intake for environmental water influx decreased the relative bias to $1-2 \%$. The acceptability of the deuterium dilution method to determine milk intake depends on the goals and the tolerance for error in group and individual intake estimates of a given study.
\end{abstract}

Human milk intake: Formula intake: Deuterium dilution: Infant nutrition

A non-invasive, isotope method for the measurement of milk intake from water flux has been used in animal studies for many years. Tritium or deuterium oxide is administered to the animal, and the rate of water flux is calculated from the product of the pool size and the tracer elimination rate. Several validation trials of the tritium or deuterium dilution method using animals have been published (Table 1; Lee \& Lifson, 1960; Macfarlane et al. 1969; Hulbert \& Dawson, 1974; Cameron et al. 1976; Green \& Dunsmore, 1978; Dove \& Freer, 1979; Doreau \& Dussap, 1980; Nagy \& Costa, 1980; Coward et al. 1982a). With the exceptions of the lizard (Uta) and kangaroo rat (Dipodomys) (Nagy \& Costa, 1980), the error of the isotope method ranged from an underestimation of $-7.0 \%$ to an overestimation of $11.5 \%$, compared with the results of conventional balance techniques. As pointed out by Nagy \& Costa (1980), the discrepancy between methods tended to increase at higher absolute humidities. Actually, the error introduced by environmental water influx was less than expected; Nagy \& Costa (1980) suggested that the magnitude of error may have varied between species, such that the errors cancelled each other to different degrees. In the animal experiments, no corrections were made for environmental water input or isotope fractionation.

An adaptation of this procedure to measure human milk intake was proposed by Coward et al. (1979). Deuterium oxide is administered to the exclusively breast-fed infant; water influx is equal to the sum of dietary water derived from human milk, metabolic water resulting from substrate oxidation, and water influx across respiratory and cutaneous 
Table 1. Validation studies in animals of the tritium or deuterium dilution technique for the measurement of milk intake

\begin{tabular}{|c|c|c|c|c|}
\hline Reference & Species & Isotope & $\begin{array}{l}\text { Absolute humidity } \\
\text { (mg water/1 air) }\end{array}$ & $\begin{array}{l}\text { Percentage } \\
\text { error* }\end{array}$ \\
\hline Lee \& Lifson (1960) & Rat & ${ }^{2} \mathrm{H}$ & - & 8.0 \\
\hline Macfarlane et al. (1969) & Lamb & ${ }^{3} \mathrm{H}$ & - & 1.0 \\
\hline Hulbert \& Dawson (1974) & Marsupials & ${ }^{3} \mathrm{H}$ & 6 to 10 & -7.0 \\
\hline Cameron et al. (1976) & Reindeer & ${ }^{3} \mathrm{H}$ & $<1.1$ to -9.4 & 1.3 to -0.1 \\
\hline Green \& Dunsmore (1978) & Rabbit & ${ }^{3} \mathrm{H}$ & $<20$ & 3.6 \\
\hline Dove \& Freer (1979) & Lamb & ${ }^{3} \mathrm{H}$ & - & $-6 \cdot 3$ \\
\hline Doreau \& Dussap (1980) & Lamb & ${ }^{2} \mathrm{H}$ & - & $-3 \cdot 2$ \\
\hline \multirow[t]{6}{*}{ Nagy \& Costa $(1980)$} & $\begin{array}{l}\text { Kangaroo rat } \\
\text { (Dipodomys) }\end{array}$ & ${ }^{3} \mathrm{H}$ & 4 to 20 & 7.7 to 44.2 \\
\hline & $\begin{array}{l}\text { Jackrabbit } \\
\text { (Lepus) }\end{array}$ & ${ }^{3} \mathrm{H}$ & 6 to 12 & $1 \cdot 1$ \\
\hline & $\begin{array}{l}\text { Monkey } \\
(\text { Alouatta })\end{array}$ & ${ }^{3} \mathrm{H}$ & 20 & $-4 \cdot 0$ \\
\hline & $\begin{array}{l}\text { Lizard } \\
(U t a)\end{array}$ & ${ }^{3} \mathrm{H}$ & 12 & $29 \cdot 1$ \\
\hline & $\begin{array}{l}\text { Lizard } \\
\text { (Sauromalus) }\end{array}$ & ${ }^{3} \mathrm{H}$ & 4 & $-2 \cdot 0$ \\
\hline & $\begin{array}{l}\text { Tortoise } \\
\text { (Gopherus) }\end{array}$ & ${ }^{3} \mathrm{H}$ & 12 & $11 \cdot 5$ \\
\hline Coward et al. (1982a) & Lamb & ${ }^{3} \mathrm{H}$ & - & $<1.0$ to 3.3 \\
\hline
\end{tabular}

* Error expressed as percentage of total water influx measured by weighing.

Table 2. Validation studies of the tracer-to-infant deuterium dilution method for estimation of milk intake

\begin{tabular}{|c|c|c|c|c|c|c|c|c|c|}
\hline \multirow{2}{*}{$\begin{array}{l}\text { Reference and } \\
\text { study area }\end{array}$} & \multirow[b]{2}{*}{$n$} & \multirow{2}{*}{$\begin{array}{c}\text { Age } \\
\text { (months) }\end{array}$} & \multirow{2}{*}{$\begin{array}{l}\text { Feeding } \\
\text { mode }\end{array}$} & \multirow{2}{*}{$\begin{array}{c}{ }^{2} \mathrm{H}_{2} \mathrm{O} \text { dose } \\
(\mathrm{g} / \mathrm{kg})\end{array}$} & \multirow[b]{2}{*}{ Sample } & \multirow{2}{*}{$\begin{array}{l}\text { Duration } \\
\text { (d) }\end{array}$} & \multirow[b]{2}{*}{ Corrections* } & \multicolumn{2}{|c|}{ Differencet } \\
\hline & & & & & & & & Mean & sD \\
\hline $\begin{array}{l}\text { Coward ef al. (1979) } \\
\text { Cambridge, UK and } \\
\text { Keneba, The Gambia }\end{array}$ & 5 & $2-4$ & $\mathrm{BF}$ & $0 \cdot 1$ & Saliva & $12-18$ & $\mathrm{GR}, r_{\mathrm{m}}$ & 12 & 16 \\
\hline Butte et al. (1983) & 14 & $2-4$ & BF & $0 \cdot 1$ & Saliva & 2 & $\mathrm{GR}, r_{\mathrm{m}}$ & 11 & 15 \\
\hline Houston, USA & 8 & $1-4$ & BF & $0 \cdot 1$ & Saliva & 5 & $\mathrm{GR}, r_{\mathrm{m}}$ & 29 & 22 \\
\hline $\begin{array}{l}\text { Vio et al. (1986) } \\
\text { Santiago, Chile }\end{array}$ & 10 & $3-9$ & FF & $0 \cdot 1$ & Saliva & 15 & $\mathrm{GR}, r_{\mathrm{m}}$ & $-1 \cdot 3$ & $4 \cdot 8$ \\
\hline $\begin{array}{l}\text { Roberts et al. (1986) } \\
\text { Cambridge, UK }\end{array}$ & 4 & $<1$ & FF & $0 \cdot 24$ & Urine & 5 & $\mathrm{GR}, f, r_{\mathfrak{g}}, r_{\mathrm{m}}$ & $5 \cdot 6$ & 1.4 \\
\hline $\begin{array}{l}\text { Lucas et al. (1987) } \\
\text { Cambridge, UK }\end{array}$ & 14 & $1-3$ & $\mathrm{FF}$ & $0 \cdot 1$ & $\begin{array}{l}\text { Urine } \\
\text { Saliva }\end{array}$ & 7 & $\mathrm{GR}, f, r_{\mathrm{g}}, r_{\mathrm{m}}, r_{\mathrm{e}}$ & $-1 \cdot 0$ & $5 \cdot 0$ \\
\hline $\begin{array}{l}\text { Fjeld et al. (1988) } \\
\text { Lima, Peru }\end{array}$ & 11 & $8-28$ & FF & $0 \cdot 1$ & Urine & $5-10$ & $\mathrm{GR}, f, r_{\mathrm{g}}, r_{\mathrm{m}}, r_{\mathrm{e}}$ & $-2 \cdot 0$ & $3 \cdot 1$ \\
\hline
\end{tabular}

$\mathrm{BF}$, breast-fed; FF, formula-fed; GR, growth rate; $r_{m}$, metabolic water; $f$, fractionation; $r_{\mathrm{g}}$, insensible water loss; $r_{\mathrm{p}}$, environmental water influx.

* Corrections incorporated into calculations.

$\uparrow$ Percentage difference between ${ }^{2} \mathrm{H}_{2} \mathrm{O}$ dilution method and direct weighing.

surfaces. The accuracy of this tracer technique has been evaluated in a number of infant trials (Table 2; Coward et al. 1979; Butte et al. 1983; Roberts et al. 1986; Vio et al. 1986; Lucas et al. 1987). The isotope method has been compared with test-weighing of human milk and pre- and post-weighing of milk formula. The difference between methods ranged 
from $-2 \cdot 0$ to $29 \cdot 0 \%$. In more recent publications, corrections have been made for isotope fractionation, insensible water losses, and respiratory and cutaneous water influx. Corrections for isotope fractionation have a minimal impact on the estimation of milk intake, in contrast to corrections for environmental water influx. Corrections for climatic conditions of high humidity and high ambient temperature may be as high as $32 \%$ of total water influx (Fjeld et al. 1988). The large discrepancies between methods reported for studies conducted in The Gambia (Coward et al. 1979) and Houston (Butte et al. 1983) may be a result of the high absolute humidities in those locales, in contrast to the more temperate climates of Santiago (Vio et al. 1986) and Cambridge (Lucas et al. 1987).

We re-evaluated the tracer-to-infant deuterium dilution method by comparing it with direct-weighing in a cohort of breast-fed and formula-fed infants in specific regard to sampling interval for isotope enrichment and correction for environmental water influx.

\section{MATERIALS AND METHODS}

Twenty breast-fed and twenty formula-fed infants were studied either at 1 or 4 months of age. All infants were products of normal-term deliveries. The mean (SD) birth weight, length, and gestational age were 3381 (SD 333) g, 500 (SD 22) $\mathrm{mm}$, and $39 \cdot 8$ weeks respectively. Gravidity (2.1 (SD 1.0)), parity (1.8 (SD 0.7)), maternal weight (64 (SD 12) $\mathrm{kg}$ ) and height $(1.63(\mathrm{SD} 0.06) \mathrm{m})$ did not differ between feeding groups; maternal age ( 30 (SD 3 ) v. 26 (SD 3) years and period of education (15 (SD 2) v. 13 (SD 2) years) were higher in the breast-feeding compared with the formula-feeding group. Infants recruited at 1 month of age were to be given either human milk or formula exclusively. Infants recruited at 4 months of age were also to be fed either human milk or formula exclusively; their diets, however, could be supplemented, not to exceed $15 \%$ of energy intake. Formulas used were Enfamil $^{\hat{\mathbb{R}}}$ (Mead Johnson and Company, Evansville, IN) and Similac ${ }^{\mathbb{B}}$ (Ross Laboratories, Columbus, $\mathrm{OH}$ ) with and without supplemental iron.

The study was approved by the Institutional Human Experimentation Committees of Baylor College of Medicine and Texas Children's Hospital, and written, informed parental consent was obtained for all studies.

\section{Design}

Approximately 1 week before the mother and infant were admitted to the Clinical Research Center (CRC) at Texas Children's Hospital, a breast-feeding consultant and health communicator from the Children's Nutrition Research Center (CNRC) visited the home to obtain health and feeding histories of the infant. A 1-month supply of ready-to-feed formula originating from one factory was provided for the formula-fed infants to minimize shifts in the natural abundances of ${ }^{2} \mathrm{H}$ in body water.

The mother and infant were admitted to the CRC for approximately $24 \mathrm{~h}$ at which time the following procedures were performed: a routine physical examination, anthropometric measurements, measurement of insensible water loss, and initiation of the deuterium dilution method. Follow-up procedures conducted at home during a $14 \mathrm{~d}$ period included daily urine sampling, a $5 \mathrm{~d}$ assessment of food intake, and final anthropometric measurements.

\section{Anthropometric measurements}

Weights of nude infants were measured on electronic, integrating Sartorius scales (Model 3862MP, Göttingen, FRG) at least $1 \mathrm{~h}$ after feeding. Weight gain was calculated as the difference between weights measured on days 1 and 14. Infant length was measured on a recumbent infant board on days 1 and 14 . 
Direct-weighing method

The intake of human milk was assessed for $5 \mathrm{~d}$ at home by test-weighing (Butte et al. 1984). Infant weights and times before and after each breast-feeding were recorded on Sartorius scales. Formula intake was determined from pre- and post-weights of $118.3 \mathrm{ml}(4 \mathrm{fl} \mathrm{oz})$ ready-to-feed formula bottles. Preweighed towels were provided to recover any formula losses. For those infants who received supplements, preweighed jars or bottles of baby foods, juices and water, and preweighed towels were supplied for the entire $14 \mathrm{~d}$ period. The type of supplement and time of feeding were recorded by the mothers. Used jars or bottles and towels were returned to the laboratory and reweighed so that the amount consumed by the infant could be recorded. Intakes were standardized over $24 \mathrm{~h}$. The manufacturer's published values (Gerber Products Company and Beech-nut Nutrition Corporation) were used in the calculations of the water contents of infant foods.

\section{Deuterium dilution method}

On day 1 of the study, $200 \mathrm{mg}{ }^{2} \mathrm{H}_{2} \mathrm{O} / \mathrm{kg}$ body-weight were administered orally to the infant from a preweighed syringe. A baseline urine sample was collected from each infant before oral administration of ${ }^{2} \mathrm{H}$. Post-dose urine samples were collected daily for $14 \mathrm{~d}$. Samples were collected in sterile, pediatric specimen bags (U-bag; Hollister Inc., Kurtsville, MO), transferred with a syringe to o-ring-sealed sample vials, and frozen at $-20^{\circ}$.

Insensible water loss was estimated by weighing the infants continuously as they slept (Sartorius scales). Infants were clothed in preweighed nappies and light, cotton hospital gowns; urine bags were affixed to the infants to prevent evaporation of urine. After the infants had fallen asleep, each was placed into the bassinet affixed to the scale; weights were recorded at $5 \mathrm{~min}$ intervals until the infant awakened. At the conclusion of the test, nappies, gowns and sheets were reweighed.

All urine samples were analysed for ${ }^{2} \mathrm{H}$ enrichment using a Finnigan Delta-E gas-isotoperatio mass spectrometer. A full description of the method is given elsewhere (Wong et al. 1987).

Milk intake was calculated according to Roberts et al. (1986), with a few minor changes. The simulation, analysis and modelling (SAAM) computer program was used to fit curves for the monoexponential decay of ${ }^{2} \mathrm{H}$ in the urine samples (Berman \& Weiss, 1978). The initial deuterium dilution space $\left(N_{1}\right)$ was calculated as

$$
N_{1}(\mathrm{~g})=\frac{d}{\mathrm{MW}} \times \frac{\mathrm{APE}}{100} \times \frac{18 \cdot 02}{\delta^{\prime} \times \mathrm{R}_{\mathrm{std}}},
$$

where $d$ is the amount of ${ }^{2} \mathrm{H}_{2} \mathrm{O}(\mathrm{g})$; MW is the molecular weight of the labelled water $(\mathrm{g} / \mathrm{mol})$; APE is the atom \% excess of the isotope in the labelled water; $\delta^{\prime}$ is the intercept or zero-time enrichment of ${ }^{2} \mathrm{H}$ over baseline; and $\mathrm{R}_{\mathrm{std}}$ is the ${ }^{2} \mathrm{H}:{ }^{1} \mathrm{H}$ ratio of V-SMOW, which has a value of 0.00015595 (De Wit et al. 1980).

The average ${ }^{2} \mathrm{H}$ dilution space, $N_{\mathrm{H}}$ was calculated as

$$
N_{\mathrm{H}}(\mathrm{g})=\left(N_{1}-N_{2}\right) / \ln \left(N_{1} / N_{2}\right),
$$

where $N_{1}$ and $N_{2}$ are the dilution spaces at time zero and at the end of the period ( $t$, in days) representing three biological half-lives of the isotope. $N_{2}$ was estimated from weight gain under the assumption that dilution spaces changed in proportion to weight during the course of the study. 
Water intake $\left(r \mathrm{H}_{2} \mathrm{O}_{\mathrm{in}}\right)$ was calculated as

$$
r \mathrm{H}_{2} \mathrm{O}_{\mathrm{in}}(\mathrm{g} / \mathrm{d})=\left[\frac{\left(N_{\mathrm{H}} \times k_{\mathrm{H}}-Q_{\mathrm{H}}\right)}{\left(1-X+X f_{1}\right)}\right]+Q_{\mathrm{H}},
$$

where $k_{\mathrm{H}}$ is the fractional turnover rate of ${ }^{2} \mathrm{H}$ and $Q_{\mathrm{H}}(\mathrm{g} / \mathrm{d})$ is the daily change in the ${ }^{2} \mathrm{H}$ dilution space, i.e. $\left(N_{1}-N_{2}\right) / t$. The proportion of insensible water loss relative to total water output is denoted by $X$. The in vivo fractionation factor $\left(f_{1}\right) 0.945$ was used for ${ }^{2} \mathrm{H}$ in water vapour.

Milk intake was calculated as

$$
\text { milk intake }(\mathrm{g} / \mathrm{d})=\frac{r \mathrm{H}_{2} \mathrm{O}_{\text {in }}-\text { water from non-milk sources }}{0.96}
$$

where the factor 0.96 represents the water content of milk plus metabolic water.

Milk intake also was calculated by deuterium dilution with correction for environmental water influx as suggested by Fjeld et al. (1988): respiratory water influx was equated to the product of absolute humidity and inspired air volume; transcutaneous water influx was based on a transcutaneous absorption rate of $0.18 \mathrm{~g} / \mathrm{m}^{2}$ per min body surface area with a $25 \%$ reduction as a result of clothing barriers. The mean absolute humidity $(0.012 \mathrm{~g} / \mathrm{l})$ was calculated from annual mean temperature and relative humidity outdoors in Houston, and from assumptions regarding indoor conditions, and indoor-outdoor time exposure. Environmental water flux was subtracted from $r \mathrm{H}_{2} \mathrm{O}_{\text {in }}$.

\section{Statistical analysis}

Student's $t$ test was used to compare feeding groups on biographical and anthropometric values. Agreement between the two methods was assessed by a technique described by Bland \& Altman (1986). First the differences between methods $v$. the means of both methods were plotted. Regression analysis was used to test for a relation between the differences and the means. The relative bias (mean difference between methods) and the $95 \%$ limits of agreement (mean difference $\pm 2 \mathrm{SD}$ of the differences) were computed. To determine if the relative bias (mean difference) was significantly different from zero, a paired $t$ test was used. Values are expressed as means and standard deviations.

\section{RESULTS}

The characteristics of the infants at the time of study are displayed in Table 3. Two formula-fed infants were eliminated from analysis because of incomplete data collection: use of bottled water was noted on dietary recall, but the quantity given was not measured which precluded comparison between the isotope and direct-weighing methods. No statistically significant differences were found between feeding groups in weight or length for the remaining thirty-eight infants. Weight gain of the formula-fed infants was higher than that of the breast-fed infants $(P<0.06)$.

Milk intakes estimated by direct-weighing are presented in Table 4. An individual's true mean was estimated to within $\pm 10.0 \%$ for the breast-fed and $\pm 6.4 \%$ for the formula-fed infants $(95 \%$ confidence interval) from the individual's $5 \mathrm{~d}$ sample mean. Five of the $4-$ month-old formula-fed infants received supplemental foods. Six of the 1-month-old infants were given supplemental water. 
Table 3. Characteristics of infants participating in the study

(Mean values and standard deviations)

\begin{tabular}{|c|c|c|c|c|c|c|c|c|}
\hline \multirow{3}{*}{ Age (months) ... } & \multicolumn{4}{|c|}{ Breast-fed infants } & \multicolumn{4}{|c|}{ Formula-fed infants } \\
\hline & \multicolumn{2}{|c|}{1} & \multicolumn{2}{|c|}{4} & \multicolumn{2}{|c|}{1} & \multicolumn{2}{|c|}{4} \\
\hline & Mean & SD & Mean & SD & Mean & SD & Mean & SD \\
\hline$n$ & 10 & & 10 & & 9 & & 9 & \\
\hline Age (d) & 32 & 3 & 114 & 10 & 33 & 4 & 113 & 9 \\
\hline Sex (male/female) & $7 / 3$ & & $5 / 5$ & & $8 / 1$ & & $5 / 4$ & \\
\hline Initial weight $(\mathrm{g})$ & 4654 & 734 & 6608 & 688 & 4618 & 194 & 6457 & 618 \\
\hline Length $(\mathrm{mm})$ & 548 & 24 & 624 & 20 & 551 & 12 & 614 & 16 \\
\hline Wt gain $(g / d)$ & $36 \cdot 6$ & $13 \cdot 6$ & $12 \cdot 2$ & $5 \cdot 0$ & $42 \cdot 9$ & $13 \cdot 1$ & $23 \cdot 3$ & $5 \cdot 5$ \\
\hline
\end{tabular}

Table 4. Assessment of intake of breast-fed and formula-fed infants by direct-weighing method* $^{*}$

(Mean values and standard deviations)

\begin{tabular}{|c|c|c|c|c|}
\hline & \multicolumn{2}{|c|}{$\begin{array}{l}\text { Breast-fed } \\
\text { infants }\end{array}$} & \multicolumn{2}{|c|}{$\begin{array}{l}\text { Formula-fed } \\
\text { infants }\end{array}$} \\
\hline & Mean & $\mathrm{SD}$ & Mean & $\mathrm{SD}$ \\
\hline$n$ & 20 & & 18 & \\
\hline Milk intake $(\mathrm{g} / \mathrm{d})$ & 752 & $169^{*}$ & 845 & 114 \\
\hline Water from food supplements $(\mathrm{g} / \mathrm{d})$ & 0 & & 29 & 62 \\
\hline Supplemental water $(\mathrm{g} / \mathrm{d})$ & 0.25 & $1 \cdot 1$ & 9 & 22 \\
\hline
\end{tabular}

* For details of procedures, see p. 6

Milk intakes estimated from deuterium dilution and the variables used in their computation are presented in Table 5. (These estimates of milk intake were based on three biological half-lives of the isotope.) Milk intakes, calculated from isotopic values corresponding to the $5 \mathrm{~d}$ in which milk intake was measured by direct-weighing, were 858 (SD 173) g/d for the breast-fed and 916 (SD 167) $\mathrm{g} / \mathrm{d}$ for the formula-fed infants (Table 6). Deuterium dilution and direct-weighing methods are compared in Table 6; milk intakes have been estimated with and without corrections for environmental water influx and insensible water loss during test-weighing (Figs 1,2). The difference between methods was consistent with increasing milk intake. The interval used in the computation of milk intake from the isotopic values (three biological half-lives $(3 \mathrm{t})$ or $5 \mathrm{~d}$ sampling interval $(5 \mathrm{~d})$ ) did not significantly influence the relative bias. The relative biases between methods (107 (SD 43) $\mathrm{g} / \mathrm{d}(3 \mathrm{t} v$. direct weighing (DW)) and 106 (SD 47) $\mathrm{g} / \mathrm{d}(5 \mathrm{~d} v$. DW)) for the breast-fed infants differed significantly from zero $(P<0.001)$. The relative biases between methods ( 64 $(\mathrm{SD} 130) \mathrm{g} / \mathrm{d}(3 \mathrm{t} v$. DW) and $70(\mathrm{SD} 155) \mathrm{g} / \mathrm{d}(5 \mathrm{~d} v$. DW) for the formula-fed infants were of borderline significance $(P<0.05$ and $P<0.07)$.

Mean environmental water influx was estimated to be $52(\mathrm{SD} 5) \mathrm{g} / \mathrm{d}$ for the breast-fed and $50(\mathrm{SD} 6) \mathrm{g} / \mathrm{d}$ for the formula-fed infants. Corrections for environmental water influx in the breast-fed infants decreased the relative bias between methods to 55 (SD 43) g/d ( $3 \mathrm{t}^{\prime} v$. DW) and 55 (SD 50) g/d ( $5 \mathrm{~d}^{\prime} v$. DW), but the biases were still significant $(P<0.001)$. The $95 \%$ limits of agreement for individuals were $154-44 \mathrm{~g} / \mathrm{d}$. Corrections for environmental 
Table 5. Milk intake of breast-fed and formula-fed infants estimated by the deuterium dilution method

(Mean values and standard deviations)

\begin{tabular}{|c|c|c|c|c|}
\hline & \multicolumn{2}{|c|}{$\begin{array}{l}\text { Breast-fed } \\
\text { infants }\end{array}$} & \multicolumn{2}{|c|}{$\begin{array}{l}\text { Formula-fed } \\
\text { infants }\end{array}$} \\
\hline \multirow[b]{2}{*}{$n$} & Mean & SD & Mean & SD \\
\hline & \multicolumn{2}{|c|}{20} & \multicolumn{2}{|c|}{18} \\
\hline$N_{\mathrm{HI}}(\mathrm{g})$ & 3463 & 505 & 3532 & 456 \\
\hline$Q_{\mathrm{H}}(\mathrm{g} / \mathrm{d})$ & 16 & 12 & 21 & 10 \\
\hline$k_{\mathrm{H}}(/ \mathrm{d})$ & $0 \cdot 236$ & 0.038 & $0 \cdot 260$ & 0.050 \\
\hline Insensible water loss $(\mathrm{g} / \mathrm{d})$ & 144 & 36 & 156 & 29 \\
\hline$r \mathrm{H}_{2} \mathrm{O}_{\text {in }}(\mathrm{g} / \mathrm{d})$ & 824 & 165 & 912 & 114 \\
\hline Milk intake $(\mathrm{g} / \mathrm{d})^{*}$ & 858 & 172 & 909 & 129 \\
\hline
\end{tabular}

$N_{\mathrm{H}}$, deuterium dilution space; $Q_{\mathrm{H}}$, daily change in ${ }^{2} \mathrm{H}$ dilution space; $k_{\mathrm{H}}$, fractional turnover rate of ${ }^{2} \mathrm{H}_{;} r \mathrm{H}_{2} \mathrm{O}_{\text {in }}$, water intake.

* Milk intake based on three biological half-lives of the isotope.

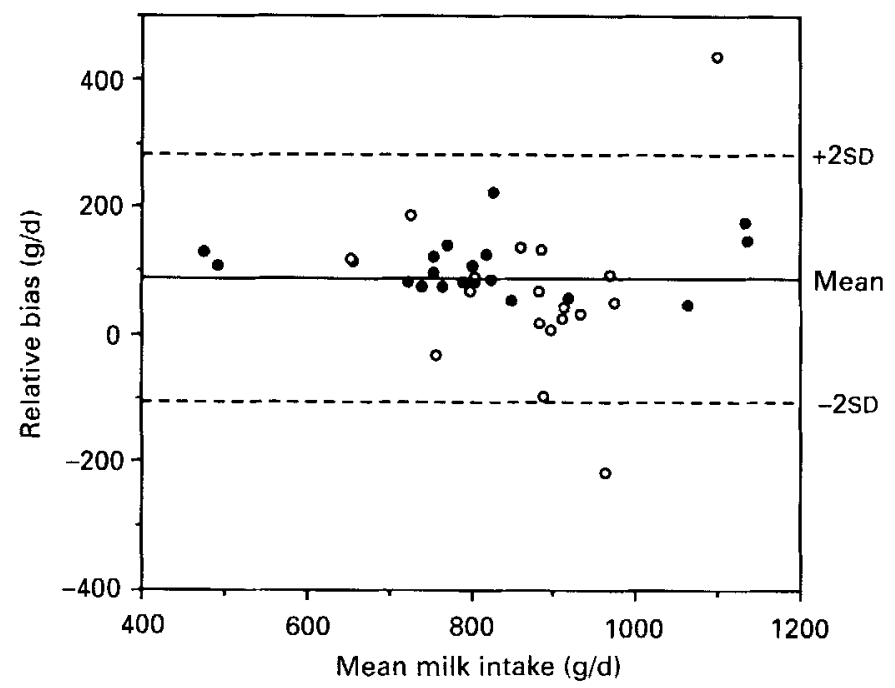

Fig. 1. Comparison between the deuterium dilution method, based on three biological half-lives of the isotope (3t), and direct-weighing (DW) methods: relative bias plotted against the mean of the two methods. Breast-fed infants; $O$, formula-fed infants.

water influx in the formula-fed infants decreased the relative bias to 8 (SD 130) $\mathrm{g} / \mathrm{d}\left(3 \mathrm{t}^{\prime} v\right.$. DW), and 14 (SD 154) $\mathrm{g} / \mathrm{d}\left(5 \mathrm{~d}^{\prime} v\right.$. DW), such that the methods agreed on average. The large standard deviations observed in the formula-fed group were partly a result of one outlying value. Elimination of this value from analysis slightly altered the relative bias as listed in Table 6; the recalculated mean differences were 42 (SD 95) (3t $v$. DW), 43 (SD 106) ( $5 \mathrm{~d} v . \mathrm{DW}),-14$ (SD 95) ( $3 \mathrm{t}^{\prime} v$. DW), and -13 (SD 106) (5 $\mathrm{d}^{\prime} v$. DW) $\mathrm{g} / \mathrm{d}$; individual variability in method agreement was still high.

A factor of $2 \%$, based on recorded feeding times and measured rates of insensible water loss, was used to correct the human milk intakes for insensible water loss during the test- 


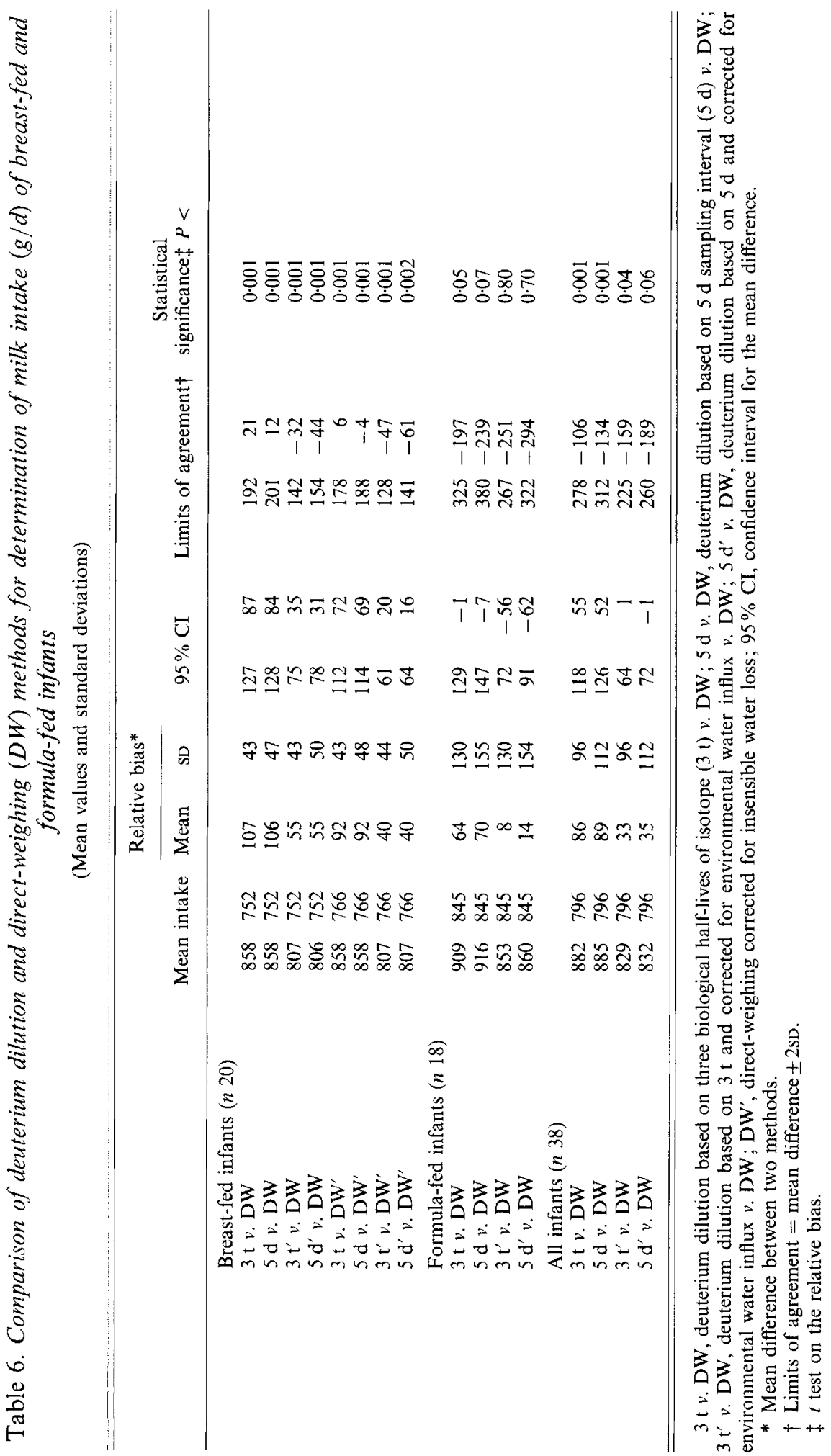




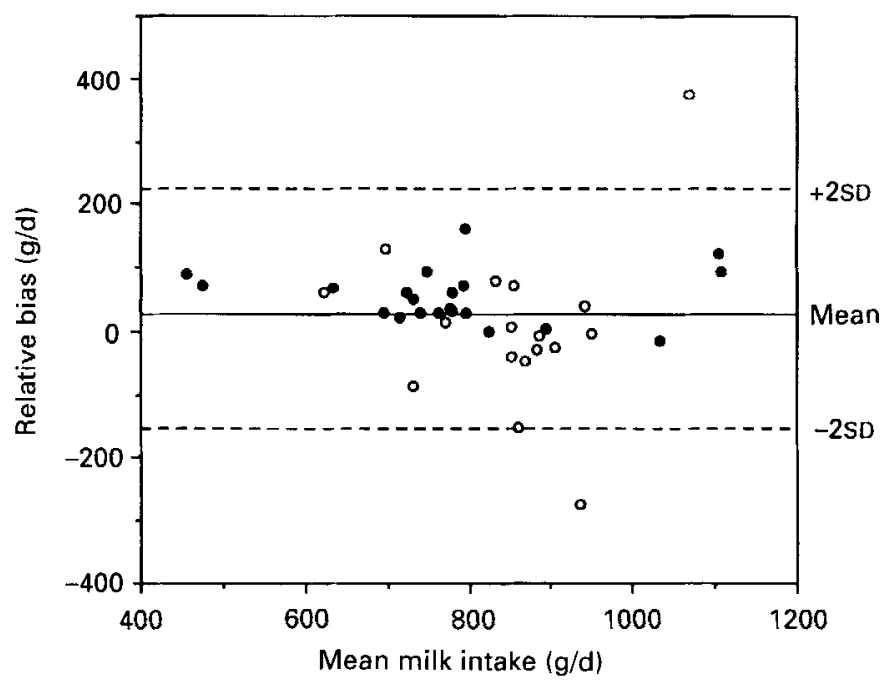

Fig. 2. Comparison between the deuterium dilution method, based on three biological half-lives of the isotope $\left(3 \mathrm{t}^{\prime}\right)$ and corrected for environmental water influx, and direct-weighing (DW) methods: relative bias plotted against the mean of the two methods. 0 , Breast-fed infants; $O$, formula-fed infants.

weighing session (Table 6). The relative bias between the test-weighing and deuterium dilution methods was decreased, but remained significant $(P<0 \cdot 001)$.

\section{DISCUSSION}

The present results indicate that the tracer-to-the-infant deuterium dilution method systematically produced values for milk intakes that were higher than those measured by direct-weighing techniques. With correction for respiratory and transcutaneous water influx, better agreement between methods was observed with the formula-fed group than with the breast-fed group. The $95 \%$ limits of agreement for individuals, however, were wide for both feeding groups. The results will be discussed as they pertain to the basic assumptions of the deuterium dilution method as outlined by Nagy \& Costa (1980), the appropriateness of the environmental water influx correction, and the discrepancy observed between breast-fed and formula-fed groups.

The deuterium dilution method for the estimation of milk intake involves several assumptions (Nagy \& Costa, 1980). First, body water volume is assumed to remain constant throughout the study interval. In the present study a linear model was used to correct the deuterium dilution space for growth. Second, water flux is assumed to be constant. The frequent feeding and urination of infants should dampen any variation in water flux; multipoint urine sampling should also minimize this source of error. Third, the method assumes that deuterium labels only body water. The exchange of deuterium, not only with body water, but also with labile hydrogens in organic matter is well recognized. The exchange results in a dilution space approximately $4 \%$ greater than the body water pool. This phenomenon of rapid isotopic exchange is accounted for by the use of the actual deuterium space (Roberts et al. 1987). Deuterium is also sequestered, and later released, during biosynthesis. Empirical values are not available from which to estimate the effect of deuterium sequestration on water turnover in infants. Studies of immature Zucker rats, however, indicated that the error on water flux from fat and protein synthesis was less than 
$2 \%$ (Haggarty \& McGaw, 1988). Nagy \& Costa (1980) concluded that isotope bound to organic matter in voided urine and faeces probably introduced negligible error in water flux in most animals. Isotope fractionation was taken into account in the calculation of water flux.

Last, probably the most unpredictable and unavoidable source of error in the deuterium dilution method as demonstrated by Nagy \& Costa (1980) is the influx of unlabelled environmental water. Fjeld et al. (1988) estimated that influx of environmental water could equal as much as $32 \%$ of total water flux in infants exposed to an absolute humidity of $31.5 \mathrm{mg} / \mathrm{l}$. Although the importance of correcting for this phenomenon is recognized, the difficulty of estimating the actual climatic conditions to which an infant is exposed is underappreciated, especially in industrialized countries where air conditioning is prevalent. In the present study, we estimated environmental water influx based on the mean annual temperature and humidity outdoors in Houston and on assumptions regarding respiratory rate, water vapour pressure of expired air, mean temperature and relative humidity indoors, proportion of time spent indoors and outdoors, transcutaneous absorption of water, and clothing, as suggested by Fjeld et al. (1988). When corrected for environmental water influx, formula intake was within $1-2 \%$ of the measured mean value. Whether this correction factor truly compensates for the intended phenomenon is unknown; it may simply counter a number of positive errors which tend to overestimate milk intake. The acceptability of this correction factor is left to the discretion of the investigator. In most field studies, however, error introduced by unreported or unmeasured water supplements is of equal or greater concern. Errors introduced by non-milk water sources are avoided in the alternative version of the deuterium dilution method, in which the mother is dosed instead of the child (Coward et al. 1982b). Close agreement has been demonstrated between test-weighing and the dose-to-mother deuterium dilution method (Butte et al. 1988). The standard deviation of the differences between methods was smaller with this alternative method than that observed with the dose-to-infant version; whether the differences are inherent to the isotope methods or incidental to subject selection has yet to be determined.

The relative bias observed for breast-fed infants was greater than that for formula-fed infants. After correcting for environmental water influx, deuterium dilution differed from test-weighing by $7 \%$ with a confidence interval of $4-10 \%$ for the mean difference. The testweighing procedure is known to underestimate human milk intake by an amount equal to insensible water loss during the course of feeding. Milk intake corrected for insensible water loss agreed more closely with the deuterium dilution values; the average difference between methods was reduced to $5 \%$ with a $95 \%$ confidence interval of $2-8 \%$.

After correction for environmental water influx and insensible water loss the relative bias observed for breast-fed and formula-fed groups differed by $3.4 \%$. Possible explanations for the discrepancy in method agreement between feeding groups are: a systematic underestimation of human milk intake by the test-weighing procedure caused by omission of feedings; underestimation of insensible water loss during breast-feeding, because this measurement was made during sleep; or overestimation of the hydration constant of human milk or the amount of metabolic water in the conversion of water influx to milk intake.

The most unavoidable and unpredictable errors in the calculation of milk intake by the deuterium dilution method are probably unreported ingestion of non-milk water and environmental water influx. Correction for environmental water influx reduced the mean difference between the deuterium dilution and the test-weighing methods in the formula-fed group, but individual variability in method agreement was high. In the breast-fed group, correction for environmental water influx and insensible water loss during breast-feeding also decreased the mean difference between the two methods, although the relative bias 
remained significant. A decision to use the tracer-to-infant deuterium dilution method to determine milk intake will depend on the goals of an investigation and specifically on the range of error that will be tolerated in error estimates of group and individual intakes.

This work is a publication of the USDA/ARS Children's Nutrition Research Center, Department of Pediatrics, Baylor College of Medicine and Texas Children's Hospital, Houston, TX. This project has been funded in part with federal funds from the US Department of Agriculture, Agriculture Research Service under Cooperative Agreement number 58-7MN1-6-100. The contents of this publication do not necessarily reflect the views or policies of the US Department of Agriculture, nor does mention of trade names, commercial products, or organizations imply endorsement by the US Government.

\section{REFERENCES}

Berman, M.\& Weiss, M. F. (1978). SAAM Manual, DHEW Publication no. (NIH) 78-180. Washington, DC: US Department of Health, Education, and Welfare.

Bland, J. M. \& Altman, D. G. (1986). Statistical methods for assessing agreement between two methods of clinical measurement. Lancet i, 307-310.

Butte, N. F., Garza, C., Smith, E. O. \& Nichols, B. L. (1983). Evaluation of the deuterium dilution technique against the test weighing procedure for the determination of breast milk intake. American Journal of Clinical Nutrition 37, 996-1003.

Butte, N. F., Garza, C., Smith, E. O. \& Nichols, B. L. (1984). Human milk intakes and growth of exclusively breast-fed infants. Journal of Pediatrics 104, 187-195.

Butte, N. F., Wong, W. W., Patterson, B. W., Garza, C. \& Klein, P. D. (1988). Human milk intake measured by administration of deuterium oxide to the mother: a comparison with the test-weighing technique. American Journal of Clinical Nutrition 47, 815-821.

Cameron, R. D., White, R. G. \& Luick, J. R. (1976). Accuracy of the tritium water dilution method for determining water flux in reindeer (Rangifer tarandus). Canadian Journal of Zoology 54, 857-862.

Coward, W. A., Cole, T. J., Gerber, H., Roberts, S. B. \& Fleet, I. (1982 a). Water turnover and the measurement of milk intake. Pflügers Archiv 393, 344-347.

Coward, W. A., Cole, T. J., Sawyer, M. N., Prentice, A. M. \& Orr-Ewing, A. K. (1982b). Breast milk intake measurement in mixed-fed infants by administration of deuterium oxide to their mothers. Human Nutrition: Clinical Nutrition 36C, 141-148.

Coward, W. A., Whitehead, R. G., Sawyer, M. B., Prentice, A. M. \& Evans, J. (1979). New method for measuring milk intakes in breast-led babies. Lancet ii, 13-14.

De Wit, J. C., Van Der Straaten, C. M. \& Mook, W. G. (1980). Determination of the absolute hydrogen isotopic ratio of V-SMOW and SLAP. Geostandards Newsletter 4, 33--36.

Doreau, M. \& Dussap, G. (1980). Estimation de la production laitière de la jument allaitante par marquage de l'eau corporelle du poulain. Reproduction, Nutrition, Développement 20, 1883-1892.

Dove, H. \& Freer, M. (1979). The accuracy of tritiated water turnover rate as an estimate of milk intake in lambs. Australian Journal of Agricultural Research 30, 725-739.

Fjeld, C. R., Brown, K. H. \& Schoeller, D. A. (1988). Validation of the deuterium oxide method for measuring average daily intake in infants. American Joumal of Clinical Nutrition 48, 671-679.

Green, B. \& Dunsmore, J. D. (1978). Turnover of tritiated water and ${ }^{22}$ sodium in captive rabbits (Oryctolagus cuniculus). Journal of Mammalogy 59, 1217.

Haggarty, P. \& McGaw, B. A. (1988). Nonrestrictive methods for measuring energy expenditure. Proceedings of the Nutrition Society 47, 365-374.

Hulbert, A. J. \& Dawson, T. J. (1974). Water metabolism in perameloid marsupials from different environments. Comparative Biochemical Physiology 47A, 617 - 633.

Lee, J. S. \& Lifson, N. (1960). Measurement of total energy and material balance in rats by means of doubly labeled water. American Journal of Physiology 199, 238-242.

Lucas, A., Ewing, G., Roberts, S. B. \& Coward, W. A. (1987). Measurement of milk intake by deuterium dilution. Archives of Disease in Childhood 62, 796-800.

Macfarlane, W. V., Howard, B. \& Siebert, B. D. (1969). Tritiated water in the measurement of milk intake and tissue growth of ruminants in the field. Nature 221, 578-579.

Nagy, K. A. \& Costa, D. P. (1980). Water flux in animals: analysis of potential errors in the tritiated water method. American Journal of Physiology 238, R454 R465.

Roberts, S. B., Coward, W. A. \& Lucas, A. (1987). Reply to letter by Wong, Butte, Garza, and Klein. American Journal of Clinical Nutrition 45, 1545-1547.

Roberts, S. B., Coward, W. A., Schlingenseipen, K.-H., Nohria, V. \& Lucas, A. (1986). Comparison of the doubly 
labeled water $\left({ }^{2} \mathrm{H}_{2}{ }^{18} \mathrm{O}\right)$ method with indirect calorimetry and a nutrient-balance study for simultaneous determination of energy expenditure, water intake, and metabolizable energy intake in preterm infants. American Journal of Clinical Nutrition 44, 315-322.

Vio, F. R., Infante, C. B., Lara, W. C., Mardones-Santander, F. \& Rosso, P. R. (1986). Validation of the deuterium dilution technique for the measurement of fluid intake in infants. Human Nutrition: Clinical Nutrition 40C, 327-332.

Wong, W. W., Lee, L. S. \& Klein, P. D. (1987). Deuterium and oxygen-18 measurements on microliter samples of urine, plasma, saliva, and human milk. American Journal of Clinical Nutrition 45, 905-913. 